\title{
Challenges of Materials Development for the Tertiary Level EFL Learners in Bangladesh: Materials Developers' Perspectives
}

\author{
Sadekul Islam ${ }^{1, *}$, Forhad Hossain ${ }^{1}$, Momtazur Rahman ${ }^{2}$ \\ ${ }^{1}$ Department of Languages, International University of Business Agriculture and Technology (IUBAT), Dhaka, Bangladesh \\ ${ }^{2}$ Department of English and Modern Languages, International University of Business Agriculture and Technology (IUBAT), Dhaka, \\ Bangladesh
}

Received September 11, 2020; Revised October 30, 2020; Accepted November 11, 2020

\section{Cite This Paper in the following Citation Styles}

(a): [1] Sadekul Islam, Forhad Hossain, Momtazur Rahman, "Challenges of Materials Development for the Tertiary Level EFL Learners in Bangladesh: Materials Developers' Perspectives," Universal Journal of Educational Research, Vol. 8, No. 12, pp. 6818 - 6830, 2020. DOI: 10.13189/ujer.2020.081248.

(b): E Sadekul Islam, Forhad Hossain, Momtazur Rahman (2020). Challenges of Materials Development for the Tertiary Level EFL Learners in Bangladesh: Materials Developers' Perspectives. Universal Journal of Educational Research, 8(8), 6818 - 6830. DOI: 10.13189/ujer.2020.081248.

Copyright $\odot 2020$ byauthors,allrightsreserved.Authorsagreethatthisarticleremainspermanentlyopenaccessunderthetermsof theCreativeCommonsAttributionLicense4.0InternationalLicense

\begin{abstract}
Quality of language teaching and efficient learning by the learners are much influenced by effective materials. Materials developers also get perplexed to decide which materials will work more; many prefer to adapt or develop their own materials but doing so requires the developers overcome a number of challenges at different stages of materials development: conducting needs analysis, setting aims and objectives, planning, drafting, pre-use assessment, piloting, production, revision and finalization. This qualitative study aims at describing those challenges in depth. Two focus group discussions with fourteen materials developers from eight private universities were conducted to collect data on materials developers' perspectives on the challenges. The findings show that lack of infrastructure and other facilities, interpersonal conflict among the stakeholders, especially the teachers and materials developers, lack of motivation and learners' poor background knowledge beget a number of challenges. It was found that the challenges can be overcome if the stakeholders are little more considerate towards the materials developers and learners' needs. The findings and recommendations provide a) implications for the administrative heads and other stakeholders and b) some guiding principles for the material developers to overcome the challenges and develop effective materials for their learners.
\end{abstract}

Keywords Materials Development, Challenges, EFL Learners, Material Developers, Perspectives

\section{Introduction}

The emergence of global community has established the role of English language in the current world. Scholars have also identified English as "English as a global language"[11], "English as a Lingua Franca" [12-14], "English as an International Language"[15-17], and "World English" [18]. Such recognition of English by the scholars have made it inevitable for each country to make their learners proficient in English to compete in the $21^{\text {st }}$ century job market and most of the countries are also investing after the teachers and materials developers to work on developing learners' skills in English.

English language teaching brings issues like content, teaching, types of students etc. Thus, dispute starts on issues like which materials are to be used to yield best output for a particular group of students. Among all the materials, good ones draw our attention most. When the existing materials and/or commercially produced materials fail to meet the teachers, learners and stakeholders' expectation, the need of materials development arises. 
'Sooner or later, every teacher of any subject comes up against a need to write materials' [1].

Each context is unique and at the same time each has resemblance to many other contexts in terms of individual learner's differences, class size, learners' needs, infrastructural facilities, and teachers' skill in materials development etc. Thus, both the teachers and material developers face a number of challenges in the whole process of materials development. Bangladesh is a developing country of South Asia. There are 106 private universities [3]. In these universities, total number of students is 3,51,691 [4]. All the universities offer some courses in English language skills for the students who are not the students of English, rather studying Engineering, Business, and Social Sciences (Economics, Sociology, Agriculture and so on). Some are basic courses and some are advanced courses. Irrespective of the courses, it is a quite common phenomenon that teachers often struggle to decide what to teach and with which material. Though many books are available to both the teachers and students, teachers still feel the need of adaptation of existing materials or development of such materials that yield best output in terms of proficiency in all skills.

This paper aims at addressing the challenges faced by the teachers and materials developers in materials development. The paper also presents the scenario of materials development of different private universities in Bangladesh to find out the experiences of materials developers in dealing with those challenges inside and outside the classroom. This research bears significance in its effort to present a number of salient features of which many are not aware, especially the university owners. Such awareness will make all the stakeholders realize the complexities in materials development process.

\subsection{Literature Review}

Materials development challenges vary from context to context; the challenges those exist in an environment might not exist somewhere else. As the materials development takes place gradually and in different stages, the challenges faced at one stage in an environment may not exist in another.

For developing materials for learners, needs analysis is the first step to many scholars. It is considered as the focus of attention for decades in curriculum design [5-6]. Without proper picture and understanding of learners' needs, it is hardly possible to produce good materials.

According to West [7], needs analysis includes two aspects: first, 'what learners will be required to do with foreign language in the target situation and second, how learners might best master the target language during the period of training.'

According to Brown [8], needs analysis (NA) is 'the systematic collection and analysis of all subjective and objective information necessary to define and validate defensible curriculum purposes that satisfy the language learning requirements of students within the context of particular institutions that that influence the learning and teaching situation.' Syllabus design and choosing effective teaching strategies greatly depend on needs analysis [9]. The idea of needs analysis was also criticized [7] and its limitations are also pointed out by many. 'In many circumstances it is difficult to predict the future needs of the learners' [9].

There is no doubt about the significance of needs analysis, but how challenging it is to specify learners' needs is a crucial question. Cowling [10] reports that there is often a lack of awareness of the existence of needs in general English courses and it is difficult to determine the specific needs of students. It is quite difficult to anticipate the needs in a homogeneous group of learners because the needs of the learner in a group may not be identical and in many cases may differ considerably from one another [7]. The lack of awareness of the existence of needs analysis as a tool in course design tends to occur due to problems of familiarity and expertise [7]. A needs analysis may come up with a range of functions and concepts which, when turned into language forms cannot be organized into a coherent teaching sequence [9].Lebedev, Pinkovetskaia, Rozhkov, and Tsybina [67] identify that it is important to conduct 'thorough students' needs analysis prior to starting a course' and 'prior to designing the course'. They also recommend that 'teachers need to highlight the skills that will be most demanded in the labor market.'

McDonough and Shaw [19] opine that textbooks that are effective in one context might fail in another. Tomlinson [20] opines that trying to consider needs of all learners end up not engaging anyone.

Tomlinson and Masuhara [21] describe that it is found that a significant amount of time and money is spent on teachers' training but the money spent for training the writers of materials is very poor. Thus, lack of knowledge and experience of writing materials is quite common. Prowse and Jacobs [22],[24] report that 'materials writers are very much influenced by existing conventions, typical topics, by typical activity types, and by typical teaching points, and not much thought is given to whether or not these accepted conventions are likely to facilitate language acquisition and development.'

Finding the lack of recommendation by the writers like Hidalgo, Hall, and Jacobs [24] and Prowse [22] for principled frameworks or criteria for materials development, Tomlinson [25] preferred to have 'an approach to materials writing in which the ongoing evaluation of the developing materials is driven by a set of agreed principles, both universal principles applicable to any learning context anywhere and local criteria specific to the target learning context(s).'

Regarding Task Design, Samuda[26] referred to by Hadfield [27] concludes that 'Task design is a complex, highly recursive and often messy process' that doesn't 
'entail orderly progressions through checklist of guiding principles'. Howard and Major (2004) [60] suggest, 'without some overall organizing principle, materials may be piecemeal and result in poorly focused activities lacking clear direction. This is frustrating and confusing for learners who may not be able to see how their English is developing'. Mishan and Timmis [28] find that gaining professional respect for the materials writers is difficult to achieve.

As theories of SLA play an important role in materials development, developers often struggle in implementing theories in the original materials development process. Tomlinson [29] explores the connection between applied linguistics theories and materials development and shows the lack of match between SLA theory and materials development practice [30].

Ghosn [31], in Tomlinson [29], describes the mismatch between what we know helps the young learners acquire L2 and what materials typically require them to do. Cohen and Ishihara [32], in Tomlinson [29], describe the mismatch between what we know about pragmatic competence and how materials typically try to help learners acquire it.

Timmis [33], in Hardwood [34], reports how feedback from the publisher caused him to effect a compromise between the principles established by the writing team prior to developing the materials and the conventional expectations of publisher, the sponsor and the Ministry of Education.

Jolly and Bolitho [1] have very effectively summarized the factors, in Tomlinson [2], that create challenges for the materials developers, 'How they respond to this need depends on all sorts of variables: the prevailing norms in a specific educational context, the amount of time available, the availability of reprographic facilities, the teacher's background and training, etc. In some contexts, teachers are expected to adhere rigidly to a prescribed course book; most teachers are too busy to contemplate writing their own material from scratch, though there are few who don't adapt their textbooks in some way; photocopying and other forms of reproduction depend on the availability of technical back-up and supplies of paper; materials evaluation, adaptation and production are often neglected or underemphasized on initial training courses.'

Prowse, [23] reports on the dissatisfaction of material writers in relation to the scope of involvement with the design of their books as they consider design as important Material design. 'Frequently a design for the look of the student page is finalized before much of the writing is done, and authors write to fit the design.' He also adds 'We have always been very involved in the design process. This can be highly rewarding if you have a good and congenial designer; it can be murder if you and the designer have different agendas. Of course, to some extent, you and the designer always have different agendas in the sense that she or he wants the design to be aesthetically pleasing and you want it to be pedagogically effective.'

Bell and Gower point [35], in Tomlinson [2], 'It may also be true that materials in which designers have too great an influence are also weakened materials commercially in the long-run. In our experience what is good design for a designer is not necessarily a good design for a teacher...there is sometimes a worrying gap between the aesthetic principles of a designer and the pedagogic principles of the writers.'

Prowse [23] also mentions that 'Some of the problems with designers may also come from the fact that they are operating on a tight budget and can only employ third-rate illustrators. They won't tell you this: they will try and convinceyou that the illustrations you are getting are actually very good.'

Regarding the challenge of developing materials in a team, Prowse [23] reports that 'There are of course, drawbacks: mismatch between individual working styles, individual writing styles, unstandardised units, a longer than usual time for decisions as we must give credit to everyone's idea in order to reach solutions agreed, if not by all members, but by a large majority.'

The success of materials greatly depends on effective piloting. Donovan [36], in Tomlinson [2], mentions major three challenges: 1.'the original authors of the material are frequently physically distanced from the piloting event', 2.'thepiloters themselves will usually have a free choice as to whether to use the materials or not (unlike teachers who may be required by their institution or their peers to use materials being specially produced for their benefit) and 3. 'thepiloters may not directly need the pilot materials as part of their teaching programme'.

There are a variety of challenges reported by different scholars. The researchers of this paper assume that it is important to study the challenges faced by the materials developers at the private universities in Bangladesh.

\subsection{Objectives of the Study}

The objectives of the study are:

i. To find out the challenges in materials development for the tertiary level students of private universities in Bangladesh

ii. To discuss materials developers' perception about the materials development challenges

iii. To recommend possible ways to overcome those challenges

\subsection{Research Questions}

a. What are the challenges in materials development for the tertiary level students?

b. How do the materials developers perceive the challenges?

c. What might make the materials developers able to overcome those challenges and produce effective materials? 


\section{Research Methodology}

'Research methodology is a way to systematically solve the research problem...in it we study the various steps that are generally adopted by a researcher in studying his research problem along with the logic behind them' [37]. In this section, the authors have discussed the following: research design, research type, research duration, sampling strategy, data collection instruments and process, and analysis of the data.

\subsection{Research Design}

This is a descriptive qualitative research in nature. The researchers interviewed the participants in two focus groups to know about the perspectives of materials developers in relation to the challenges they face in the materials development process. 'Focus group discussion is a nondirective technique that results in the controlled production of a discussion of a group of people' [38]. In focus group discussion a researcher interviews a group of individuals to know the personal experiences, beliefs, perceptions about a topic and attitudes of the participants towards the topic of discussion. Such discussion takes place through a moderated interaction [39-42].

\subsection{The Participants}

The researchers followed purposive sampling, a nonrandom sampling [43], to select the participants of focus group discussions. In a purposive sampling the investigators use personal judgment to select a sample because they expect and believe, based on prior information, that the sample will provide the data they need [43]. According to Lederman[44], the participants in focus group discussion are the 'purposive' samples of the target population. He [44] also suggests that the number of participants in a focus group discussion can range from 6 to 12 people. Eight participants participated [43] in the first focus group discussion and 6 participated [44] in the second focus group discussion. They were selected from 8 different private universities in Bangladesh. The researchers considered that more than one focus group meetings [45] would present a comprehensive view on the topic, so they conducted two focus group discussions.

The participants of the first focus group discussion were chosen from top ranked universities (1-20 in the ranking) [46]. These universities are comparatively older and well-known in the country. The participants of the second focus group discussion were chosen from the universities that are comparatively newer than the other universities. The researchers assumed that the scenario in the top ranked universities may not exist in the comparatively newer universities.

The researchers knew them personally and believed that they would provide necessary information with enough patience. Among the participants, two were Associate Professors, eight were Assistant Professors, two were Senior Lecturers and 2 were Lecturers. Teachers of different levels, in terms of their age and designation, were chosen as the researchers assumed that the perceptions of junior and senior teachers might be different. The lecturers were junior to the professors. The Associate Professors accomplished their $\mathrm{PhD}$; while the other participants completed at least Masters Degree in Applied Linguistics and English Language Teaching (ELT) from two reputed public universities in Bangladesh: University of Dhaka and Jahangirnagar University. Two of the participants completed Cambridge English Language Assessment (CELTA) under the British Council, Bangladesh. All the participants have been teaching for minimum five to fifteen years in their respective universities. They are also much involved in teaching general English courses to the students who are studying in the first year (the first three semesters) in those universities. The participants were very willing to engage in the group discussion and the researchers strongly believed that they could generate useful data from the participants, most importantly because they belonged to a homogenous group: all were both teacher and material developers of similar social and educational context [47]. They were chosen mainly for three reasons: $a$. it was convenient to persuade them for the focus group discussion, b. they were reliable sources of data collection to the researchers and c. they all had background of English Language Teaching and experience of teaching and materials development in their institutions.

After selecting the participants, the researchers invited them to join the discussion in a convenient venue. The venue was very comfortable and only the participants joined in the discussion in a room where there was almost no form of distraction [48]. It was a round table discussion where there was enough seating space so that the participants can see each other and can have smooth interaction [49].

\subsection{Data Collection Instruments}

The current study utilized focus group discussion to collect data from the key informants [43]. Audio and tape recording, note - taking and participant observation are the main methods of data collection during a focus group discussion [50].

So, the data were all verbal responses from the participants. The researchers recorded the whole conversation among the participants, transcribed the audio and later on took note from the recorded conversation. Important points were also transcribed and have been presented here. The focus group discussion was conducted mostly in English but the participants also responded in Bengali as well to some extent. The questions asked to the participants were mostly open ended but with guided questions as, in qualitative study, '...questions should be 
asked in a truly open-ended fashion so people can respond in their own words. The truly open-ended question allows the person being interviewed to select from among that person's full repertoire of possible responses those that are most salient'[51]. In addition, the researchers spent time in writing post-meeting summary. The participants were called in case any point was not clear to the researchers or a point needs further elaboration [51].

Before the focus-group discussions, the researchers prepared a set of open ended questions to discuss in the meeting. The participants were asked what challenges they face at different stages of materials development. The idea of how many steps are there in materials development has been coined from Mishan and Timmis [28]. They discuss the 'Idealized Sequence' that consists of stages that material workers work through in 'Materials Design: From Process to Product'[28].According to them there are 8 stages: 1.Statement of Beliefs, 3.Needs Analysis, 3. Aims and Objectives, 4. Syllabus Design, 5. Drafting, 6. Piloting, 7. Production, 8. Revision. For the convenience of discussion, the researchers grouped the stages into 1.Planning Stage (Needs Analysis, Aims and Objectives, Syllabus Design) 2. Development Stage (Drafting), 3.Pre-use Assessment Stage (Drafting) 4.Implementation Stage (Piloting) 5.Post-use Evaluation (Production and Revision)

The moderator tried to ensure that the smooth flow of discussion is not disrupted by too much interference and kept the discussion on track [52-54]. As the participants did not agree to allow the researchers to video the discussion, one of the researchers observed non-verbal interactions and the impact of group dynamics to supplement the data $[41,55]$. We did so as non-verbal data in combination with verbal data provide 'thicker' description and interpretations [56].

\subsection{Data Analysis}

The responses from the participants were recorded and later on transcribed. The part of the discussion where the participants commented on Bengali was translated into English and then transcribed. After the focus group discussion, we listened to the tapes and took more notes that we possibly missed during the discussion. 'Note-expansion' approach where 'the reporter (note taker) listens to the tape in order to clarify certain issues or to confirm that all the main points are included in the notes" [57] was followed to add the missed points. The questions were already categorized into several themes, so it was easy for us to identify major themes discussed in the focus group and categorized the themes. In the next stage, we analyzed the comments of all participants, compared the comments, and noted the points of agreement and disagreement on the themes.

\section{Research Findings}

In this section, the researchers have described, in some cases summarized, the answers provided by the participants, and compared the observations of participants. Fourteen teachers participated in the two focus group discussions. While reporting their comments or quoting them, we have used a numerical number for them like Materials Developer 1 (MD-1), Materials Developer 2 (MD-2) and so on. The findings include only those observations that the researchers found more critical. It also happened that participants added to their opinions later over phone as they did not want to say everything in front of the materials developers who are from the other universities. They did so as they did not want to criticize the practices of their own university in the discussion.

\subsection{Planning Stage (Needs Analysis, Aims and Objectives, Syllabus Design)}

\subsubsection{How challenging is it to conduct needs analysis?}

The participants were asked how much challenging it is to conduct needs analysis. One participant reported that identifying the learners' needs is tough for many reasons. There is hardly any scope for identifying learners' needs as the institutions have a pre-set curriculum. They just group the students into several groups. Contents are not selected based on what the students want to learn. MD-6 reported that flawless grouping cannot be ensured always for many reasons: 'I cannot meet the learners' need because most often I have mixed classes where the students possess different levels of efficiency and they are from different disciplines. Thus I lose the interest of identifying learners' need as I cannot meet the needs of all learners. In that case, I prefer to teach a predetermined set of topics.'

\subsubsection{How is it difficult to set objectives? What factors make it challenging to set objectives?}

The issue of mixed ability class and the failure of identifying learners' specific needs were supported by the other participants; almost all of them face the similar experience in their institutions. They further linked this issue to our next question. We asked them how challenging it is to set objectives. Six of the participants brought the issue of mixed classes. As the learners' needs are not specified to accordingly, they often struggle to set objectives. Inability to set effective objectives for all also influences the materials development process. It was found that the materials developers cannot set objectives keeping the interest of all learners. As the participants are material developers and teachers at the same time, they judge the students' level in the first few classes and then reshuffle the course or lesson objectives to some extent. Two said that they can hardly bring changes once the semester has started.

3.1.3. How much challenging is it to select content and put them in appropriate sequence?

According to Nunan [58], selection of the content should 
be justified. The materials developers were then asked how challenging is it to select content and arranging them in appropriate order. MD 5 reported, 'I have a list of topics but most often I get puzzled and I can't decide which topic I should bring first while developing materials. What to teach first is mostly the concern of teachers. It is also similarly puzzling to me as I think of the teachers who are going to use the developed materials in a class.'MD-6 reported that, while developing materials, she does not think that much about the sequence; instead she follows a sequence based on her subjective judgment. But the individual learner differences [59] keep her obsessed with confusion.

\subsubsection{Do you care about quality design in materials development? How is it related to good materials?}

By quality design the researchers mean the layout of the developed materials: either as handout or chapter or a book. MD-5 reported that most often they cannot care much about quality design. It happens most often with the teachers- materials developers as they have work load. It was also reported that the well designed materials hold the students' attention more, but the organizational context always does not support that. Sometimes they do not have the skill of designing in Adobe Photoshop or Illustrator. Sometimes they do not spend enough time for layout as they cannot print them in color or cannot make the colorful version available for the students. MD-2 reported that they cannot concentrate much on quality design as it increases the price of the materials that might reduce the interest of the learners to collect the materials. MD-1 told that she gets all supports to ensure quality design. She does not have the skill of using Photoshop or Illustrator, but the university has a technical team that prepares an attractive layout.

\subsubsection{How do you see the role of infrastructural facilities and financial assistance in the planning stage?}

On this issue, some of the participants were little hesitant to talk as they thought that their true opinions might go against their institution or might defame the image of their institution. Two of the participants reported that they do not face any challenge in materials development due to lack of infrastructural facilities. They also get financial assistance from the authority for developing materials. The rest of the participants reported many factors that make the materials development task challenging. Those include a. University cannot/do not arrange small class (for lack of budget or for it is running on a rented building and, therefore, there are not good number of classrooms or for the university wants to minimize cost for maximizing profit) and developing materials for a large class becomes a hectic job b. Though the universities (two participants reported) facilitate funding for research and spend on buying books and electronic resources, they don't spend on materials development; it is also difficult to make them (university authority) understand the need of own materials. Lack of budget and availability of infrastructural facilities are dominant challenges to $90 \%$ of the participants of the second focus group.

\subsubsection{Do you think about national curriculum while designing materials?}

In both focus group discussions, all of the participants reported that they do not think about national curriculum. They focus on the curriculum of their respective institutions. Recently, there is a shift in education; the government has promoted Outcome Based Education (OBE). As it is new in Bangladesh, the materials developers reported that, though they have received training, they do not have enough skill in transforming the current trend into Outcome Based Education. The training they received is not enough to them. Thus, this recent shift has brought some new challenges.

\subsection{Development Stage (Drafting)}

\subsubsection{How much freedom do you enjoy in materials development?}

Six of the participants (focus group -1) reported that they are not free to develop whatever materials they want; while two reported that they enjoy absolute freedom in materials development. The senior teachers enjoy more freedom in materials selection than that of the juniors. One participant from a reputed university reported that whatever she produces has to be submitted to her head of the department. She added, 'I am fine with that. It can improve my work but when I feel my materials were good but not accepted well, I feel depressed to some extent. Again, whether materials are good or bad can be analyzed. So, I take the whole process as part of learning. I am free to produce any materials I want but I have to get approval from my senior before I use them in the classes.' MD-2 reported that there is a scope of argument to decide what materials to produce but the whole process remains under supervision. Such supervision is very helpful for the materials developers but the seniors do not find it comfortable as they think they are experienced and supervision is redundant or it curves the flourish of potential of materials developers. MD-5 reported that she finds the supervision helpful but sometimes it makes her less creative, ultimately less effective. MD-11 reported that he has to make compromise while preparing materials. As his university is not like the other top ranking universities, it is more concerned about the number of students. He had to prepare easy materials irrespective of the quality of the students to make sure that all the students can secure good results in the examinations.

\subsubsection{How difficult is it to develop an appropriate test?}

'We can develop standard test but there are lot of issues that most often debar us from doing so. We have mixed class as many have already mentioned. How can it be possible to judge different types of students with the same 
test? Besides, the university most often doesn't allow us to prepare challenging questions as they think students might not pass and ultimately they will drop out', reported by MD-10. One reported that there should be someone to evaluate the standard of test but they most often do not receive such feedback. All the participants of both focus group discussions supported the issue of mixed ability class but they only partially agreed on other challenges. Some of the universities prefer challenging questions so that the learners learn better and they also think that standard test establishes the reputation of the institution.

\subsubsection{Do you receive appropriate and timely feedback on your work? How feedback plays a role in material development?}

They unanimously agreed that feedback plays a significant role in materials development. Especially, if they receive feedback from someone who is both a teacher and materials developer, the feedback is more effective as the person can provide insight on the effectiveness of the materials from the classroom practice perspective. Three of the participants (focus group-1) reported that they always do not receive timely feedback, but later they are criticized if the materials are not enough satisfactory to them. Three reported that they are supposed to prepare materials much ahead of the class so that they get enough time for revising and editing their lessons upon the feedback provided by the department head. Two participants (focus group-2) reported that feedback giving culture has not grown yet in their institutions. They ask for feedback from their colleagues with whom they are in good terms. Such feedback is often very informal but helpful.

\subsubsection{How does criticism impact your work? How much resistance do you face?}

This question was asked considering the social context of Bangladesh. It happens that teachers do not want to accept new materials, especially the teachers who are used to using their old materials with which they are comfortable. Besides, a good number of old teachers are not capable of using technology in language teaching. So, they show resistance; neither do they welcome new materials, nor they want to use those in their classes. It was reported that many teachers cannot adopt new materials, while many do not want to as they think they have been teaching for many years and their old materials are perfect. Thus, there is a resistance to accept new materials. Many teachers follow the new materials not because they believe that these are effective, but because they are guided to or forced to do so. Other materials developers reported that sometimes resistance is shown without any explanation and criticisms are not constructive. MD-12 and 13 (focus group 2) reported that materials are not shared among the materials developers and teachers in their university. MD-14 reported, 'I am scared of sharing materials with others greatly because I don't know how others will welcome this approach'.

\subsubsection{How does time constraint influence the quality of materials?}

As the materials developers have to carry load of teaching, taking exams, examining the scripts, conducting research and so on like the other teachers, sometimes they do not get enough time to ensure the quality of materials as they plan or as they believe it should be. MD 2 reported 'I have to teach a number of courses in my university. Each course is different; assessment is different. It's very tough for me to produce quality materials for each course. It is not about only developing contents for teaching; we have to develop tests as well. So, what we do is we share materials. If we don't do so, I feel it's tough to produce equally good materials for all courses'.

\subsubsection{How challenging is it to develop materials in a team?}

As there is work pressure, a follow up question was asked. How much effective is the team work? MD-8 reported, 'Team work is time saving for all but as there are many minds, there are many opinions as well. All the members of a team do not agree on a material always. Even if a member doesn't agree on something, still he or she has to follow materials produced by his fellow colleagues with some chances to improvise. Thus, we save time and at the same time we try to use comparatively better materials in our classes.' Others reported that though there are chances of disagreement, it is useful to work in a team. Peer learning also facilitates materials development learning. As there is lack of training, it can be an alternative to training as well to some extent. MD-9 expressed his regret that he hardly could get the likeminded people with whom he could develop or exchange materials. There are also some people who do not want to work, but they are very willing to get the unethical acknowledgement as materials writers.

\subsubsection{How much motivated do you find yourself to develop materials?}

It was an interesting question to all. It is undeniably true that if materials developers are not motivated to produce their own materials, there is hardly any use of thinking of materials development. There are a number of reasons that motivate them in materials development like need of professional development, sense of belongingness towards the students and institutions, and appreciation from fellow colleagues. Materials developers pointed out different issues that demotivate them. The following quotes highlight how it is difficult to hold motivation in the whole process of materials development.

MD -3: 'I feel demotivated when I see that my institution is not evaluating my effort in annual appraisal.'

MD -4: 'I don't feel about annual appraisal. I feel like it's my job to prepare my own materials and it's important part of teaching.' 
MD -7: 'As there is no punishment or reward for putting extra effort to develop materials, I can hardly hold my motivation, though I put effort to produce materials.'

MD -10: 'I always feel the urge to improve myself as both materials developers and teacher. So I like to work hard to develop materials for my students. The work load sometimes demotiavates me.'

MD -11: 'Whenever I do not receive appropriate feedback from my seniors or my students, I feel demotivated.'

MD -12: 'I try to prepare good materials, but when I see that I am not always allowed to use them in my class or I cannot use them. I wonder why I put that effort!'

It was found that the Lecturers and Assistant Professors were more motivated in comparison to the Associate Professors.

\subsection{Pre-use Assessment Stage (Drafting)}

\subsubsection{How is it challenging to assess materials before you implement?}

As many materials developers are young and not much trained in materials development, it is important, if it is possible, to have some feedback from the expert for pre-assessment. Most of the materials developers reported that they receive feedback mostly from their department head who might be an expert as well in the same field. Materials developers of top ranked universities do not need to struggle to receive expert opinion as their department heads are expert or they have experts as adjunct faculty. But the new universities can hardly recruit experts. Thus, there is hardly anyone to guide the materials development. One of the participants, the head of the department of English of university X, reported, 'I am the department head, though I am very young. Most often I feel the need of experts. I know I do not deserve to be the head, but I am only because my university is in a remote place from the capital Dhaka. Even sometimes I cannot decide whether my materials are good or not.'

\subsection{Implementation Stage (Piloting)}

3.4.1. How do you see the role of implementation of newly developed materials to identify their effectiveness?

After the primary assessment of new materials, the implementation of the developed materials is the next stage. Piloting the materials can also be challenging for many reasons. The materials developers consider this stage very crucial as this stage can give them a clear view of their materials in terms of appropriateness and effectiveness. Materials Developer-5 reported that, in his university, they use the new materials in the classroom both as part of teaching and piloting the materials. MD-6 reported, 'we use the primary drafted materials in the classroom to see how good they are; later we improve the materials based on the classroom experience.'

\subsubsection{How do you deal with poor implementation of materials?}

Sometimes teachers are found not much interested in implementing the new materials greatly because they do not see much professional benefit in it as such performance does not bear any importance in the annual appraisal. Some other reasons that coerce the teachers not to use the new materials are: 1.Teachers are used to using the old materials, 2.They possess a sort of Superiority Complex and feel like their materials are better, 3 . Juniors prepared the materials, 4.New materials can give them discomfort, 5 . There is a lack of proper monitoring and 6 . Some do not possess that belongingness as they were not involved in materials development. They requested the teachers with whom they were in good terms to implement the new materials in their classes and provide feedback. Materials developers mentioned the need for monitoring and reported that whether the teachers are using the materials appropriately is not often monitored. MD-8 reported that observer is not much welcomed by the teachers in his university, so it is embarrassing both for the teachers and observers. MD-11 reported that there is hardly any culture of monitoring the implementation of new materials. The absence of such practice makes it embarrassing for all.

\subsection{Post-use Evaluation (Production and Revision)}

\subsubsection{How do you re-assess materials?}

After receiving feedback on the materials, the materials developers' task is to re-assess the materials in order to decide what sort of editing or revision is necessary to make the materials more effective. Two scenarios were found in this regard. One is that enough feedback is not available for the material developers; the other is that many teachers suggest many changes depending on their classroom teaching experience. MD-8 reported, 'It is really tough, sometimes, impossible to incorporate the received suggestions. Sometimes, the teachers ask to include/exclude a topic but do not provide the justification'. One MD reported that, 'I simply make the changes suggested by my department head; I believe the head is much more experienced than I and the suggestions will help improve my materials. Sometimes, though I do not want, I make the necessary changes as I find it safer. I do it to avoid any conflict.'

\subsubsection{How difficult is to edit and revise the materials?}

It was reported that editing and revising materials are not that challenging when they receive appropriate and timely feedback. Time constraint is the biggest challenge in editing and revising task. Sometimes the materials developer, especially if they are both materials developers and teachers, do not get enough time to introduce the changes as they plan to. One participant (focus group 2) reported that 'I stay in office almost for the whole day like my colleagues. I do not have personal PC in my office. 
There are some that we can use, but not whenever we need. After going home, I most often feel exhausted. As a result, I can hardly focus on editing and revising the materials. Though I have willingness to do the job but I don't get enough support. I do not get much salary to buy a laptop for me. If my university provides me desktop facility, I believe I will work better.'

\subsubsection{How do you finalize materials?}

According to most of the participants, finalizing the materials include two issues: 1.including new contents, revising the present contents or excluding whole or part of contents, and 2. balancing the learners' needs and authority's expectation in finalizing the list of contents. The materials developers finalize the list of contents to be kept in the syllabus but they cannot unanimously agree on certain contents. Certain confusions remain unsolved, untouched. Such circumstance makes the materials developers compromise in different forms in the process of finalizing materials. Revising the contents is not that much challenging to the materials developers provided with that there is someone to guide except some challenges like time constraint and lack of support, especially technical support.

\section{Discussion}

It is understood that the challenges are diverse in nature and many in numbers. Many of them are quite subjective and, if those are challenges or not, depend on the perspective of individuals. It can also be speculated that it will involve ardent response from all the stakeholders to make the tasks of materials developers easier. A wide range of action plan is required to help materials developers overcome the challenges and reach their goals staying in line with the university mission, vision and the expectations from the graduates in the country. Undoubtedly, as the challenges are distinctive in many cases in many institutions, each institution will require different action plans to face them. Among the challenges came out from the discussion, the challenges faced in planning stage and implementation seem most crucial as there are many issues that are beyond the control of the materials developers.

'Materials writing is at its most effective when it is turned to the needs of a particular group of learners' [1]. Under any circumstances the learners' needs must not be sacrificed. When there is hardly any scope to conduct a formal needs analysis, the materials developers can do two things: 1.observe and diagnose the students level (in case the materials developers are the teachers as well), and then they can think of materials instead of preparing materials before they start any class and test those to see how appropriate they are. 2. Ask the teachers to start with some contents, observe how the students perform and report on students' performance (in case the materials developers are not themselves the teachers)

The issue of mixed ability classes seems the most dominating in the whole process of materials development. As, in the given context, mixed ability classes cannot be avoided, to solve the problem of setting objectives, materials developers can include activities of different levels and put additional contents. They expect that the good students will be able to finish early, and the weak students will take time. Even if the weak students cannot finish the same tasks, they are offered alternative activities that are already put as additional contents. Though the materials developers do not think it is a feasible practice, but they reported that they can reduce gap by doing so. It is also true that some universities cannot reduce the class size like the well established universities those are expensive. If it is not possible to arrange smaller classes for all courses, it can be arranged for few beginning courses as they are more important to build the basic skills. If they can select contents very carefully to build the basic in the beginning courses, it can be expected that students in the later semesters will face less difficulty even if the classes are comparatively larger. Materials developers can think of overcoming some of the challenges of materials development for mixed classes through effective classroom teaching strategies.

Tomlinson and Masuhara [21] refer to Maley [61, 62] and Bao [63] in their discussion to talk about flexibility. Maley [61, 62] emphasizes the importance of flexibility in materials design and Bao [63] offers practical suggestions for designing flexibility. Maley [61] advocates for 'providing greater flexibility in decision about content, order, pace and procedures.' According to him, flexibility will allow teachers to supplement and adapt the materials. In short, flexibility and freedom of materials design can be really effective for all the stakeholders.

When materials developers find it confusing to select contents, they can adopt a number of strategies. Teachers who are already teaching a similar course can be asked which contents they teach and which of these the students prefer to learn. If the materials developers are teachers, they can take few days to identify areas where students are weak. A tally can be prepared that includes areas of weakness, number of students weak in the same areas etc. Instead of following a set curriculum, data collection on the learners learning styles and needs can play a significant role here. After collecting data, a normal frequency analysis can guide materials developers in content selection and sequence. Donovan's suggestion [36] can be useful for those who are simultaneously teachers and materials developers. He suggests, 'individual teachers will be able to choose materials for their classes. But more often the decision to be made across a group of teachers by a director of studies or by a head teacher, or any combination of these parties, frequently in consultation with, or with the approval of, parents.'

'Physical appearance and production of materials is 
important both for motivation and for classroom effectiveness' [1]. Teachers can be trained on making attractive layout using Microsoft Word, PowerPoint initially. It will not be expensive for universities, even for the new ones. Gradually, on the basis of designing specific needs, materials developers can get short term or long term training on use of Adobe Photoshop or Adobe Illustrator. Bell and Gower [35] suggest 'Also there are real and necessary pedagogic constraints which designers have to accept as well as design constraints that authors have to accept. Sometimes it is necessary pedagogically to sacrifice illustration for words (texts, rubrics, etc.) in order to make a series of activities work in the classroom, just as it is sometimes necessary to cut back on, say, a practice activity to make it fit in with an adequately spaced visual' [22].

As Bangladesh is just a developing country, lack of financial assistance is not something very unusual. If materials developers can accept the constraints and try to use the limited resources efficiently, the damage for lack of facilities can be minimized. A little positive and sacrificing attitude of the writers can bring the solution. Howard and Major [60] suggest, 'teachers must be realistic about what they can achieve in terms of materials and production within the limitations of available resources and facilities.' Materials developers should negotiate with the authority and be able to convince them for investment in materials development.

In case of developing standard test, the materials developers must be realistic. There should be a balance between the plan of materials developers and the expectations of the university authority. In case of mixed ability classes, the test should include both easy and challenging tasks so that poor students do not find it too difficult and good students find it too easy. If weak students do very poor in the test, a second test can be arranged only for those students who are struggling. Only the simplification of test to reduce to drop out or to save the interest of the university will be destruction and develop a false confidence among the students. Tomlinson [64] opines, 'most materials developers recognize the need to help learners to develop confidence but many of them attempt to do so through a process of simplification. They try to help the learners to feel successful by asking them to use simple language to accomplish easy tasks. This approach is welcomed by many teachers and learners. But in my experience it often only succeeds in diminishing the learners. They become aware that the process is being simplified for them and that what they are doing bears little resemblance to actual use of language.'

Challenges like negative criticism, time constraint, working in a team can be easily handled if the materials developers can motivate themselves to put some additional effort beyond their regular day to day responsibility and take all these as a part of their professional development.
Tomlinson [21] suggests 'you can only eventually become an effective materials developer by actually developing materials and through reflection, self- evaluation and constructive criticism.'

If the University Grants Commission (UGC) of Bangladesh strictly monitors whether the universities are recruiting the minimum number of expert in each discipline, all the universities will be bound to recruit experts. The individual institution can also recruit by themselves willingly for the greater interest of learners. Recruiting one or two experts will not be much expensive as well. Part-time consultant can also be managed by the universities. The experts can both give feedback to the works of the materials developers and facilitate the professional development of teachers and materials developers.

Understanding the effectiveness of materials may require a number of semesters. Using materials only for one or two semesters and taking decision whether to keep it or not might not be wise, especially for the universities that can spend less on materials development. As the universities and their staff develop their own materials and no third party is involved, they can take as much time as they feel is necessary. 'Cambridge University Presse's Cambridge English for schools was used in pilot form by around 5,000/ learners over two years, in classes in various countries' [36]. If the teachers do not want to use only the new materials, they can be requested to use the materials as supplementary materials integrating these into the main teaching programme [36]. Donovan [36] opines, 'If the pilot material can survive some initial reluctance and reservations, or the feedback can point out the source of this to the writers, this will be to the benefit of the process.' Materials developers can convince some teachers who are not willing or motivated to pilot the new materials by saying, prior to the piloting, that the piloters name will be acknowledged in the final publication [36]. Donovan [36] suggests the acknowledgement of piloters either by their name or that of their institution 'can give strong professional satisfaction.'

If the taught contents do not work much or are not clear to the students, the materials developers should get feedback from both the teachers and materials to re-asses the materials. Feak and Swales [65] and Johnson [66] prescribe that the materials writers are to be willing to 'write, re-write and re-write again'. The universities should reduce the general work load of the materials developers so that they can spend enough time. University can also assign some people who will be dedicated to materials development. They can overtly declare as well that contribution in materials development will be appreciated in annual appraisal. Most of the universities consider publication as an influential criterion in their annual performance appraisal structure. They can also include contribution of teachers to materials development. 


\section{Conclusions}

The findings show that the challenges at different stages are created greatly for 1 . Lack of infrastructure and investment that ultimately creates deficiencies in many areas like lack of expert, unavailability of small class room/desired class size, lack of planning from the very beginning, lack of budget for materials development and training for the materials developers etc. 2. Interpersonal conflict among the teachers, and developers 3.Lack of motivation from the materials developers' side for various reasons and 4.Lack of awareness among the students and their background knowledge. The financial resources related challenges can be overcome if the university authority really wants to serve the students' purpose. But the interpersonal conflict seems a never ending issue and deserves special attention as it silently hinders the materials development process.

The observations and opinions came out of the discussion present an inclusive picture of materials development challenges but not a complete picture. It is really needed to find out the real picture of more universities. Such exploration will ultimately contribute to the learners' holistic development in terms of language proficiency. So, all the stakeholders should be more considerate and liberal for the sake of students' future. This issue deserves further attention and more group discussions and interviews will definitely give clearer and in depth scenario of materials development across the private universities. In future, large scale research, both qualitative and quantitative in nature, should also be conducted to establish a culture of structured and effective materials development. As the context of each university is different and there are many salient issues, a thorough investigation by the respective institution is also inevitable.

\section{REFERENCES}

[1] Jolly, D., Rod Bolitho, “A Framework for Materials Writing’. In Tomlinson, B. (Ed.), Materials development in language teaching, Cambridge: Language Teaching Library, Cambridge University press, 1998, pp. 95-116.

[2] Tomlinson, B. (Ed.), Materials development in language teaching, Cambridge: Language Teaching Library, Cambridge University press, 1998, pp. 2.

[3] Online Available: http://www.ugc-universities.gov.bd/priva te-universities. Online available from: http://www.ugc.gov. bd/

[4] Online available:http://data.banbeis.gov.bd/images/ban008. pdf. online available from: http://data.banbeis.gov.bd/

[5] Munby, J., Communicative Syllabus Design, Cambridge: Cambridge University Press, 1978.

[6] Brown, J. D., 'Foreign and second language needs analysis',
In Long, M. H. \& Doughty, C. J. (Eds.), The handbook of language teaching, Oxford: Blackwell, 2009, pp. 269-293.

[7] West, R., 'Needs analysis in language teaching', Language teaching, Vol.27, no.1, pp. 1-19,1994. DOI: https://doi.org/10.1017/S0261444800007527

[8] Brown, J. D, The elements of language curriculum: A systematic approach to program development, Heinle\& Heinle Publishers, Boston, MA 02116, 1995.

[9] Cunnings worth, A., 'Needs analysis-A review of the state of the art. System', Vol.11,no.2, pp.149-154, 1983. https://doi.org/10.1016/0346-251X(83)90025-8

[10] Cowling, J. D., 'Needs analysis: Planning a syllabus for a series of intensive workplace courses at a leading Japanese company', English for specific purposes, Vol.26,no.4, pp.426-442, 2007. https://doi.org/10.1016/j.esp.2006.10.003

[11] Crystal, D, English as a Global Language, 1st Ed., Cambridge: Cambridge University Press, 1997.

[12] House, J., "Misunderstanding in intercultural communication: Interactions in English as a lingua franca and the myth of mutual intelligibility”. In: Gnutzmann, C. (Ed.) Teaching and Learning English as a Global Language. Stauffenberg, Tübingen, Germany, pp.73-93, 1999. DOI: 10.12691/education-2-9-20

[13] Seidlhofer, B., 'Closing a conceptual gap: The case for a description of English as a Lingua Franca,' International Journal of Applied Linguistics, Vol.11, no.2, pp.133-158, 2001.https://doi.org/10.1111/1473-4192.00011

[14] Jenkins, J., English as a Lingua Franca: Attitude and identity, Oxford: Oxford University Press, 2007.

[15] Widdowson, H. G., 'The forum: EIL, ESL, EFL: Global issues and local interests', World Englishes, Vol.16, no.1, pp.135-146, 1997.https://doi.org/10.1111/1467-971X.00054

[16] Modiano, M., 'International English in the global village', English Today, Vol.20, no.3, pp.3-15, 1999. DOI: https://doi.org/10.1017/S026607840001083X

[17] Jenkins, J., The phonology of English as an International Language, Oxford: Oxford University Press, 2000.

[18] Brutt-Griffler, J., World English: A study of its development, Clevedon and Buffalo: Multilingual Matters, 2002.

[19] McDonough, J., Shaw, C., Materials and Methods in ELT, Oxford: Blackwell, 1993.

[20] Tomlinson, B., 'Humanizing the course book'. Developing materials for language teaching, 2003, pp.162-173.

[21] Tomlinson, B., \&Masuhara, H., The complete guide to the theory and practice of materials development for language learning, John Wiley \& Sons, 2017.http://ebookcentral.proq uest.com

[22] Prowse, P., 'How writers write: Testimony from authors'. In Tomlinson, B. (ED.), Materials development in language teaching, Cambridge: Cambridge University Press, 1998, pp. 130-145.

[23] Prowse, P., 'How writers write: Testimony from authors'. In B. Tomlinson (ED.), Materials development in language teaching, $2^{\text {nd }}$ ed., Cambridge: Cambridge University Press, 
2001, pp. 151-153.

[24] Hidalgo, A. C., Hall, D.,, Jacobs, G. M. (Eds.). Getting started: Materials writers on materials writing. SEAMEO Regional Language Centre, 1995.

[25] Tomlinson, B., Materials development for language learning and teaching, Language teaching, Vol.45,no.2, pp.143-179, 2012. doi:10.1017/S0261444811000528

[26] Samuda, V., 'Expertise in pedagogic task design'. In Expertise in second language learning and teaching, Palgrave Macmillan, London, 2005, pp. 230-254.

[27] Hadfield, J., 'Chaosmos: Spontaneity and order in the materials design process', In English language teaching textbooks, Palgrave Macmillan, London, 2014, pp. 320-359.

[28] Mishan, F., Materials development for TESOL, Edinburgh University Press, 2015.

[29] Tomlinson, B.(Ed.), Applied linguistics and materials development, London: Bloomsbury, 2013.

[30] Tomlinson, B., 'Second language acquisition and materials development', In Tomlinson, B. (Ed.), Applied linguistics and materials development, London: Bloomsbury, 2013, pp.11-30.

[31] Ghosn, I. K., 'Language learning for young learners', In Tomlinson, B.(Ed.), Applied linguistics and materials development, London: Bloomsbury, 2013, pp.61-74.

[32] Cohen, A,. D., \& Ishihara, N., 'Pragmatics', In B. Tomlinson (Ed.), Applied linguistics and materials development, London: Bloomsbury, 2013, pp.113-126.

[33] Timmis, I., 'Writing materials for publication: Questions raised and lessons learned'. In N. Hardwood (Ed.), English Language Teaching Textbooks; Content, consumption, production, Basingstoke: Palgrave Macmillan, London, 2014 pp. 241-261.

[34] Hardwood, N. (Ed.), English Language Teaching Textbooks: Content, consumption, production, Basingstoke: Palgrave Macmillan, London, 2014, pp. 241-261.

[35] Bell, J., Gower, R., 'writing course materials for the world: A great compromise'. In Tomlinson, B. (Ed.), Materials development in language teaching, Cambridge: Language Teaching Library, Cambridge University press, 1998, pp.116-129.

[36] Donovan, P., 'Piloting-a publisher's view’, In Tomlinson, B. (Ed.), Materials development in language teaching, Cambridge: Language Teaching Library, Cambridge University press, 1998, pp.149-189.

[37] Kothari, C. R., Research methodology: Methods and techniques, New Age International, 2004.

[38] Flores, J. G.,, Alonso, C. G. (1995), 'Using focus groups in educational research: Exploring teachers' perspectives on educational change', Evaluation Review, Vol.19,no.1, pp.84-101, 1995. https://doi.org/10.1177/0193841X950190 0104

[39] Cornwall, A., Jewkes, R., 'What is participatory research?'. Social science \& medicine, Vol.41, no.12, 1667-1676, 1995.https://doi.org/10.1016/0277-9536(95)00127-S
[40] Hayward, C., Simpson, L., Wood, L., 'Still left out in the cold: problematising participatory research and development', Sociologia Ruralis, Vol,44, no.1, pp.95-108, 2004, https://doi.org/10.1111/j.14679523.2004.00264.x

[41] Kitzinger, J., 'The methodology of focus groups: the importance of interaction between research participants', Sociology of health \& illness, Vol.16, no.1, pp.103-121, 1994.https://doi.org/10.1111/14679566.ep11347023

[42] Morgan, D. L., "Focus groups." Annual review of sociology, Vol. 22, no. 1, pp. 129-152. 1996 https://doi.org/10.1146/annurev.soc.22.1.129

[43] Frankel, J. R., Wallen, N. E., 'Single-subject research’, How to design and evaluate research in education, 7th ed, New York, NY: McGraw-Hill, 2009.

[44] Lederman, L. C., 'Assessing educational effectiveness: The focus group interview as a technique for data collection', Communication education, Vol.39, no.2, pp.117-127, 1990.https://doi.org/10.1080/03634529009378794

[45] Burrows, D., Kendall, S., 'Focus groups: what are they and how can they be used in nursing and health care research?', Social Sciences in Health, Vol.3, pp.244-253, 1997.

[46] Online available:

https://www.dhakatribune.com/bangladesh/education/2019/ 05/25/what-has-changed-since-2017, Online available from: https://www.dhakatribune.com/ (accessed March,22,2020)

[47] Krueger, R. A., Focus groups: A practical guide for applied research, 2nd ed, Thousand Oaks, CA: Sage Publications, 1994.

[48] Smith, J. M., Interviewing in Market and Social Research, London: Routledge and Kegan Paul, 1972.

[49] Sampson, P., 'Qualitative research and motivation research', Consumer market research handbook, Vol. 3, no. 30, 1972.

[50] Stewart, W. D., Shamdasani, N. P., Rook, WD, Recruiting focus group participants and designing the interview guide in focus groups, 2007, pp. 51-69.DOI: https://dx.doi.org/10 .4135/9781412991841.d22

[51] Patton, M. Q., 'Qualitative interviewing', In Qualitative research and evaluation methods, Sage Publications. 2002, pp. 344-347, 384-385.

[52] Carey, MA, Smith, MW, 'Enhancement of validity through qualitative approaches: Incorporating the patient's perspective,' Evaluation and the Health Professions, Vol.15,no.4,pp.107-114,1992. https://doi.org/10.1177\%2F016327879201500107

[53] Carey, MA, 'The group effect in focus groups: planning, implementing, and interpreting focus group research'. In: J M Morse (ed.) Critical Issues in Qualitative Research Methods, Sage, Thousand Oaks, 1994, pp. 225-241.

[54] Sim, J., 'Collecting and analysing qualitative data: issues raised by the focus group', Journal of advanced nursing, Vol.28, no.2, 345-352, 1998. https://doi.org/10.1046/j.1365 $-2648.1998 .00692 . \mathrm{x}$

[55] Kitzinger, J., "Qualitative research: introducing focus groups. "Bmj 311, no.7000, pp.299-302, 1995. doi: https://doi.org/ 10. 1136/bmj.311.7000.299 
[56] Fonteyn, M. E., Vettese, M., Lancaster, D. R., \& Bauer-Wu, S., 'Developing a codebook to guide content analysis of expressive writing transcripts'. Applied Nursing Research, Vol.21,no3, pp.165-168, 2008.doi.org/10.1016/j.apnr.2006 .08 .005

[57] Bertrand, J. T., Brown, J. E., \& Ward, V. M., 'Techniques for analyzing focus group data’, Evaluation review, Vol.16, no.2, 198-209, 1992. https://doi.org/10.1177/0193841X920 1600206

[58] Nunan, D., Candlin, C. N., Widdowson, H. G., Syllabus design, Vol. 55, Oxford: Oxford University Press, 1988.

[59] Rod, E., The study of second language acquisition, Oxford University Press, 1994.

[60] Howard, J., \& Major, J., 'Guidelines for designing effective English language teaching materials', The TESOLANZ Journal, Vol.12, no.10, pp. 50-58, 2004.https://www.resear chgate.net/publication/237476568_Guidelines_for_Designi ng_Effective_English_Language_Teaching_Materials

[61] Maley, A. 'Squaring the circle- reconciling materials as constraint with materials as empowerment', In Tomlinson, B. (Ed.), Materials development for language teaching, Cambridge: Cambridge University Press, 1998, pp. 279-294.

[62] Maley, A. (2011). Squaring the circle- reconciling materials as constraint with materials as empowerment. In B.
Tomlinson (Ed.), Materials development for language teaching, $2^{\text {nd }}$ ed, pp. 379-402, Cambridge: Cambridge University Press.

[63] Bao, D., 3 FLEXIBILITY IN SECOND LANGUAGE MATERIALS. The European Journal of Applied Linguistics and TEFL, Vol.4, no.2, pp.37-53, 2015, https://www.researchgate.net/publication/327415247_Flexi bility_in_second_language_materials

[64] Tomlinson, B., 'Introduction', In Tomlinson, (Ed.), Materials development in language teaching, Cambridge: Language Teaching Library, Cambridge University press, 1998, pp.1-23.

[65] Feak, C. B., Swales, J. M., 'Tensions between the old and the new in EAP textbook revision: A tale of two projects'. In English language teaching textbooks, Palgrave Macmillan, London, 2014, pp.299-319.

[66] Johnson, K., Designing language teaching tasks, Basingstoke: palgrave Macmillan, 2003, pp. 196-205.

[67] Lebedev, A. V., Pinkovetskaia, I. S., Rozhkov, M. A., Tsybina, L. V., 'Implementation and Peculiarities of English for Specific Purposes Course Design at Ogarev's Mordovia State University', Universal Journal of Educational Research, Vol.8,no.1, pp.178-182, 2020. https://doi.org/10. 13189/ujer.2020.080122 